\title{
Developing a method for real-time visualization of cellulase activity
}

\author{
Pallavi Kumaria ${ }^{a}$ Tali Sayas ${ }^{\mathrm{a}}$, Patricia Bucki ${ }^{\mathrm{c}}$, Sigal Brown Miyara ${ }^{\mathrm{c}}$, and Maya Kleimana,b* \\ ${ }^{a}$ Institute of Plant Sciences, Agricultural Research Organization (Volcani Center), Rishon Lezion 7505101, Israel \\ ${ }^{\mathrm{b}}$ Agro-NanoTechnology and Advanced Materials Center, Agricultural Research Organization (Volcani Center), \\ Rishon LeZiyyon, Israel \\ ${ }^{\mathrm{c}}$ Institute of Plant Protection, Agricultural Research Organization (Volcani Center), Rishon Lezion 7505101, Israel \\ ${ }^{*}$ Corresponding author: mayakl@ volcani.agri.gov.il
}

\begin{abstract}
Studying the interactions between microorganisms and plant roots is crucial for understanding a variety of phenomena concerning crop yield and health. The role of root surface properties in these interactions, is rarely addressed. To this end, we previously built a synthetic system, from the inert polymer polydimethyl siloxane (PDMS), mimicking the root surface microstructure, using a replication technique. This replica enables the study of isolated effects of surface structure on microorganism-plant interactions. Since the root surface is composed mostly of cellulose, using celluloselike materials as our replica, instead of PDMS, is the next logical step. This will enable following the hydrolysis of such surfaces as a result of microorganisms secreting Plant Cell Wall Degrading Enzymes (PCWDE), and in particular, cellulase. Visualization of such hydrolysis in a synthetic system can assist in studying the localization and activity of microorganisms and how they correlate with surface microtopography, separately from chemical plant signals.

In this work, we modified the known carboxymethyl cellulase (CMC) hydrolysis visualization method to enable realtime tracking of cellulase activity of microorganisms on the surface. Surface was formed from pure CMC, rather than CMC incorporated in agar as is often done, and by that, eliminating diffusion issues. Acridine orange dye, which is compatible, at low concentrations, with microorganisms, as opposed to other routinely used dyes, was incorporated into the film. The dye disassociated from the film when hydrolysis occurred, forming a halo surrounding the point of hydrolysis. This enabled real-time visualization since the common need for post hydrolysis dyeing was negated. Using Root Knot Nematode (RKN) as a model organism that penetrates the plant root, we showed it was possible to follow microorganism cellulase secretion on the surface in the form of CMC film hydrolysis. Furthermore, the addition of natural additives, in the form of root extract was also shown to be an option and resulted in an increased RKN response. We tested our newly developed method by changing temperature and $\mathrm{pH}$ conditions and by characterization of the hydrolyzed surface using both Scanning Electron Microscopy (SEM) and Atomic Force Microscopy (AFM).

This method will be implemented in the future on a root surface microstructure replica. We believe the combination of this new method with our previously developed root surface microstructure replication technique can open a new avenue of research in the field of plant root-microorganism interactions.
\end{abstract}

\section{Introduction}

The first point of interaction between the plant and an associated microorganism occurs on the surface of the plant. The surface of the plant, while covered with waxes in some cases such as leaves of certain plant species, is composed mostly of cellulose $\mathrm{e}^{1-3}$. Cellulose is the most abundant biopolymer on earth, it is one of the main structural components 
of plants, together with hemicellulose and lignin ${ }^{4-6}$. Cellulose is composed of D-glucose units covalently linked via $\beta$-1,4-glycosidic bonds ${ }^{7,8}$, forming a spatial arrangement with crystalline and amorphous parts. The cellulose chains are arranged as a sheet within the crystalline fibers and connected with inter or intra molecular hydrogen bonds. It is, therefore insoluble in water and many organic solvents ${ }^{7}$. During the interaction between the plant surface and microorganism, plant cellulose is often hydrolyzed. In particular, soil borne plant pathogens often enter the plant through the cellulose-rich root surface, with the aid of secreted Plant Cell Wall Degrading Enzymes (PCWDE), including cellulase ${ }^{9,10}$. This phenomenon is of great interest to phytopathologists studying the complex set of interactions between plants and microorganisms.

Cellulose hydrolysis can also be utilized for other purposes. For example, the enzymatic hydrolysis of cellulose into fermentable sugars and their subsequent conversion into a variety of potential chemicals and biofuels, has been widely investigated for a long time ${ }^{11}$. The search for microorganisms to be used in cellulose hydrolysis for fuel production has yielded a variety of detection methods for cellulase activity ${ }^{12}$. Visualization of the hydrolysis process is a simple approach to achieve fast and semi-quantitative estimates of the hydrolysis. Surface based cellulose hydrolysis detection methods have been developed over the years, however, using cellulose as a substrate is challenging, mostly due to its crystalline sites causing aggregation ${ }^{7}$. Hence, many of the detection methods largely rely on the visualization of hydrolysis of the cellulose derivative carboxymethyl cellulose (CMC) ${ }^{13}$.

$\mathrm{CMC}$ is the most widely used cellulose derivative for studying cellulytic activity by microorganisms ${ }^{13}$. CMC is soluble in water and this property is used to incorporate CMC into gel-like substrates such as agar or gelrite, which is the most common method for studying cellulase activity when using this derivative ${ }^{14-17}$. The microorganisms to be inspected are cultured on a gel-like medium containing CMC, leaving sufficient time for hydrolysis activity to occur. The medium is then dyed with a dye that interacts only with either CMC or the hydrolysis products, differentiating the hydrolysis zone by a changed color, enabling visualization of the hydrolysis that occurred ${ }^{18,19}$. In the past, a variety of dyes have been introduced for post hydrolysis plate staining, the most common of which are Gram's iodine and Congo red $^{19,20}$. The use of these dyes poses several problems, for example, the films can be washed off after staining or the hydrolysis zone is not always easily discernible ${ }^{21}$. These issues restrict the ability to accurately quantify the hydrolysis. While the use of CMC and dye as a platform for cellulase detection in microorganisms has been investigated over the years for different application, almost no attention was given to the spatial resolution of the microorganisms cellulase activity on plant tissues. Johnsen et al. discussed the importance of spatial resolution in the context of cellulase activity on plant tissue prints ${ }^{20}$. In this study, solidified CMC films and CMC in solution were used to better quantify the hydrolysis ${ }^{20}$. However, the dyeing process was still performed after the hydrolysis reaction was completed, eliminating real-time visualization of the hydrolysis process.

Spatial resolution can be crucial in the context of plant interactions with microorganisms, and highly relevant for studying plant-pathogen interactions. For example, though some soil borne pathogens are known to enter the root in specific locations ${ }^{22-24}$, the structural basis for this preference has received little attention. Additionally, synthetic systems were proven efficient in depicting the structural preference in leaves ${ }^{25,26}$. We recently introduced a synthetic method to study structural preferences in soil borne pathogens ${ }^{27}$. Our method involves the replication of the root surface microstructure in a synthetic system in order to study the spatial preferences in root pathogens localization on 
the root surface. We demonstrated replication of tomato root surface microstructure using the silicone-based polymer - polydimethyl siloxane (PDMS). However, PDMS replicated root surfaces do not interact with the pathogen and are mostly valuable in determining pathogen localization. Out method is not limited in the choice of material and any material that can generate a film can be used to replicate the root surface microstructure.

Here, we develop a novel method for cellulase activity visualization. Our method is based on CMC films tagged by acridine orange, a biocompatible dye, for real-time screening of cellulase activity. This method is a cheap and easy way to study cellulytic activity. In this study, we tagged CMC with acridine orange through an adsorption process, generating dyed films. This prevents the need for post hydrolysis staining, enabling a reliable and reproducible visualization and detection, under real-time conditions of enzymatic hydrolysis. We used both synthetic cellulase as well as a live root pathogen representative (Root knot nematode - RKN) under various parameters. Our method has the potential to be expanded to detect spatial distribution of cellulytic activity of many living microorganism sources. For example, a dyed CMC based root surface replica could be used both as a structural replica of the root, and as a reactive surface, upon which cellulose hydrolysis by cellulase secreted from soil borne pathogens can be investigated.

\section{Results and Discussion}

Our goal was to establish a system that enables real-time visualization of cellulase secretion by microorganisms on surfaces, allowing us to later proceed to biomimetic plant surfaces. We chose CMC as our surface material since it forms a 3D gel-like structure in an aqueous environment and hence can be used in its pure form to investigate cellulase activity $^{28}$, specifically with a spatial resolution that might be prevented when mixed with other materials ${ }^{20}$. In addition, it is widely used as a reagent for cellulase activity investigation in various applications ${ }^{29-34}$. We chose acridine orange as a dye to visualize hydrolysis since it is a cationic dye and therefore is highly soluble in water and compatible with $\mathrm{CMC}^{35}$. Additionally, it enables the incorporation of microorganisms into the system since its toxicity is limited ${ }^{36}$. Acridine orange is a versatile fluorescent dye, mostly used for cell staining as well as for RNA and DNA staining in living cells and gels ${ }^{37}$. Visualization of enzymatic hydrolysis of CMC films by synthetic cellulase is shown in Figure 1 , under hydrolysis optimal parameters ${ }^{38}: \mathrm{pH}$ value of 5 and incubation at $37^{\circ} \mathrm{C}$ for $2 \mathrm{~h}$. This hydrolysis produced a clear halo where the enzyme was added, which was not visible in the control film (Figure 1). The halo formation was due to CMC hydrolysis resulting in the release of incorporated dye. Two other dyes examined were found to be inferior to acridine orange. Both are widely used in the literature and are often compared ${ }^{19,21,39}$. Congo red was easily washed out of the film, regardless of cellulase activity and using gram's iodine resulted in an unclear hydrolysis zone.

We further wanted to establish that the formed halo is indeed the result of CMC hydrolysis. This was done by testing for the presence of reducing sugars (such as glucose) in a solution using Benedict's test ${ }^{40}$. The reaction between the sugar and the sodium ion in Benedict's reagent causes the formation of enols. In turn, $\mathrm{Cu}^{2+}$ present in the test solution is reduced to $\mathrm{Cu}^{+}$resulting in a color change and a precipitation occurring due to insolubility in water upon boiling ${ }^{40}$. The color varies from green to dark red or rusty-brown, depending on the amount and type of sugar. For the purpose of Benedict's test, we allowed the reaction to continue for $18 \mathrm{~h}$, to generate sufficient amount of glucose for detection. Both the control and the reacted film were washed with a measured amount of water. Initially, the water in the enzyme treatment (solution II) was slightly colored as opposed to water from the control film (solution I) due to the release of 
acridine orange dye from the film (Figure 1A). The wash solutions were then subjected to Benedict's test and a distinct rusty red precipitate appeared in solution II, indicating the presence of reducing sugars in the water that originated from the reactive film, but not in the control wash (Figure 1B). A bright blue color was observed in the control wash, due to the presence of $\mathrm{Cu}^{2+}$ in Benedict's solution.

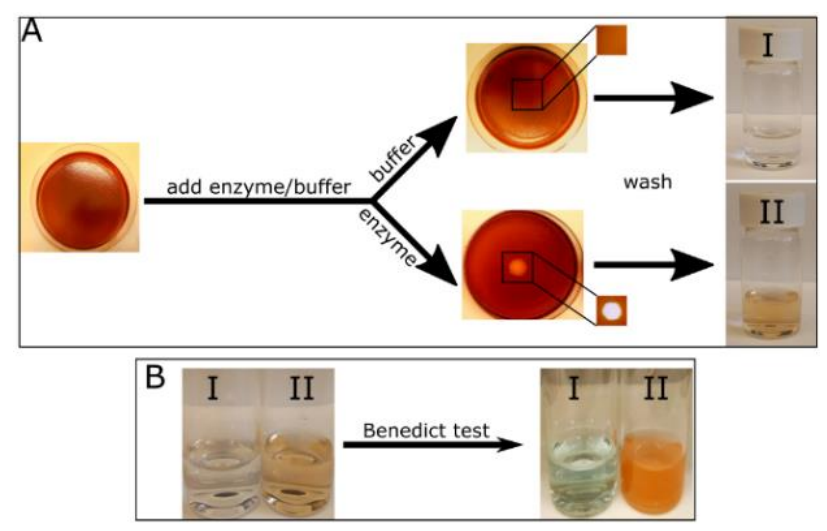

Figure 1: Enzymatic hydrolysis of CMC film tagged with acridine orange. Dyed CMC films, pre-treated with acetate buffer, were subjected to either $10 \mu \mathrm{l}$ acetate buffer (I) or $10 \mu \mathrm{l}$ containing $10 \mu \mathrm{g}$ cellulase (II). The films were incubated at $37^{\circ} \mathrm{C}$ for $2 \mathrm{~h}$, after which, a clear halo was formed only on the film subjected to the enzyme (A, middle section, with enlargement of relevant area). The films were then washed with $20 \mathrm{ml}$ distilled water, which was collected into a vial. Only the water collected from the film subjected to the enzyme showed a change in color (A, right side). The washed water was then subjected to Benedict's test clearly showing the presence of sugars only in the washed water from the film subjected to the enzyme (B).

To determine quantitatively the extent of the hydrolytic activity, we performed a dose response assay with increasing enzyme concentrations. We used concentrations ranging from 1 to $30 \mu \mathrm{g} / 10 \mu \mathrm{l}$, keeping the volume constant at $10 \mu \mathrm{l}$, eliminating possible liquid volume effects. The films were prewashed with acetate buffer at $\mathrm{pH} 5$ and incubated at $37^{\circ} \mathrm{C}$ for $2 \mathrm{~h}$. Representative images showing halo size and color resulting from various enzyme concentrations are shown in Figure 2A. As can be seen from the images, both size and hues change with increasing amount of enzyme. All films started out uniformly at a thickness of $1 \mathrm{~mm}$. Film hydrolysis leads to change in hue in the hydrolyzed region, probably due to consumption of film thickness, and reaches saturation when all film thickness is consumed. Since saturation in hue change occurred before maximal enzyme amount, we chose halo surface area for a reliable quantification. Surface area quantification represents hydrolysis level, which in turn, represents the amount of enzyme. The quantification of halo surface area as a function of enzyme concentration is shown in Figure 2B. We chose the four higher concentrations, in which the hue was dominated by a white color. The results show a linear correlation $\left(R^{2}=0.9745\right)$ between enzyme concentration and halo area. Since halo hue could not be used for quantification of hydrolysis due to saturation effect, we used UV-Vis spectroscopy of wash solutions for that purpose. As hydrolysis of CMC results in the release of acridine orange from the film, we used the known maximum absorbance wavelength of acridine orange at $480 \mathrm{~nm}$ to assess the amount of dye released from the film. We then calculated what percentage of the acridine orange added to the film was released during the hydrolysis (Figure 2C). Our analysis shows that dye release increased with enzyme quantity (Figure 2C). The highest enzyme concentration $(20 \mu \mathrm{g} / 10 \mu \mathrm{l})$ resulted in aggregated dye, probably due to the high concentration of dye released from the film parts. The absorbance was, hence, lower than that detected with the lower concentration $(15 \mu \mathrm{g} / 10 \mu \mathrm{l})$ and so we consider $15 \mu \mathrm{g} / 10 \mu \mathrm{l}$ as the limit of detection using the acridine orange absorbance method. We further wanted to assure that indeed the phenomenon we see occurs due to CMC hydrolysis by cellulase and it is quantifiable. We did that by analyzing the wash products using Sumner's method. In this method, 3,5-Dinitrosalicylic acid is subjected to the tested solution. In the presence of reducing sugars, and upon boiling, 3,5-Dinitrosalicylic acid is reduced to 3-Amino-5-nitrosalicylic acid, which 
strongly absorbs light at $540 \mathrm{~nm}$. To perform this assay, we used undyed CMC films, to prevent the noise in absorbance that may occur from the dye. We also performed the reaction for $16 \mathrm{~h}$, since we needed to produce enough reducing sugars to overcome the sensitivity of the assay. We calculated the weight of reducing sugars released as a percentage of the CMC in the original film (Figure 2D). We found that at low enzyme concentrations, the amount of products was undetectable using this method, but as the enzyme concentration went up, so did the amount of reducing sugars (Figure 2D). All measurements gave roughly the same percentage of CMC hydrolysis, including the halo, when calculated as percentage of total area (data not shown). Quantification of the enzymatic reaction is often performed to assess microorganisms hydrolysis ability. The quantification is usually performed by measuring the hydrolysis products and is mostly done in solution using multiple techniques ${ }^{38,41-43}$. Some methods were developed for hydrolysis quantification on a surface by measuring the halo size and indeed a correlation was found between enzyme units and halo size. However, this was performed on an agar plate mixed with CMC, which presents a different reaction and diffusion pattern than the ones developed here ${ }^{44,45}$. We showed that activity is increasing with increasing enzyme concentration, using various methods, but more importantly, we showed that the most sensitive and accurate method is the visualization method, which is the method we aim to develop in this assay. The halo was consistently larger with increasing enzyme concentration and was clearly visible and quantifiable at both low and high enzyme concentrations. We do not aim at using the halo size as quantification between different assays as it may vary depending on the conditions of the assay. However, we have shown that it can be used to compare two different experiments performed at the same conditions.

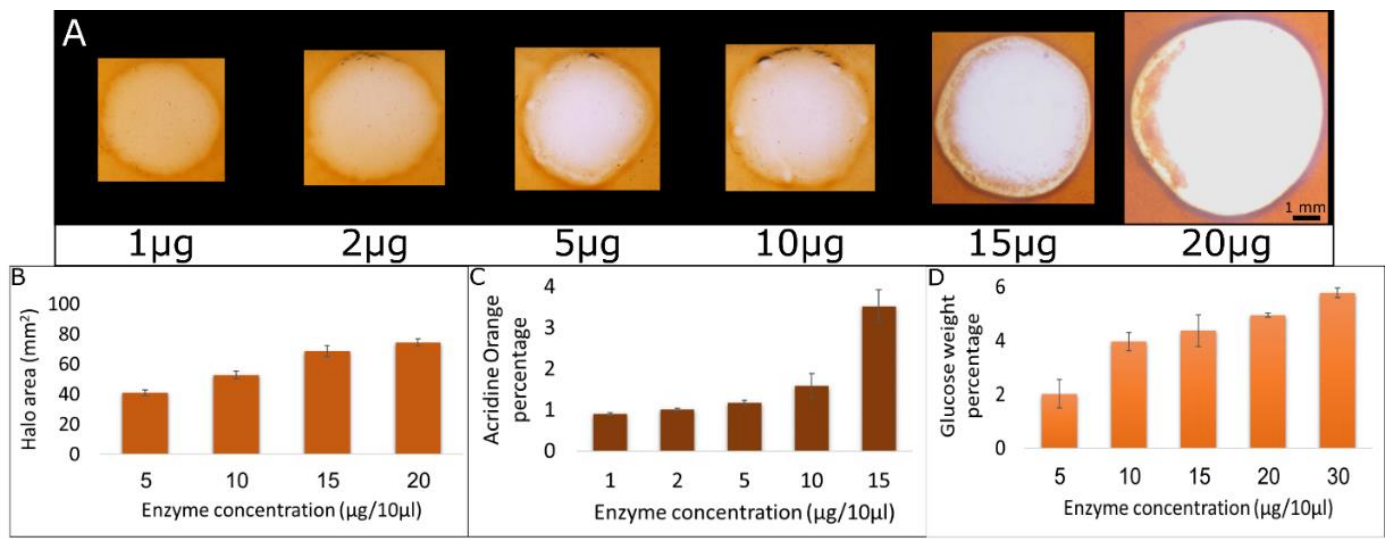

Figure 2: Halo size, dye and hydrolysis products correlation with enzyme concentration. Halo size was visualized (A) and measured (B) on films subjected to different enzyme concentrations. Film wash water was analyzed using UV-vis spectroscopy (C) and Sumner's method followed by UV-vis spectroscopy (D). A CMC dyed film was subjected to $10 \mu \mathrm{l}$ of different amounts of cellulase. The films were incubated at $37^{\circ} \mathrm{C}$ for $2 \mathrm{~h}$ and washed with $20 \mathrm{ml}$ water. The halo was visualized (A), measured (B) and wash water was analyzed using UV-vis spectroscopy. The absorbance at $480 \mathrm{~nm}$ was used to calculate acridine orange concentration based on a calibration curve and the percentage of dye released by hydrolysis (C). Additionally, CMC films with no dye were subjected to different amounts of cellulase for $16 \mathrm{~h}$ at $37^{\circ} \mathrm{C}$. Wash water was subjected to Sumner's method. Absorbance was measured using UV-vis. Absorbance at 540nm was used to calculate reducing sugars concentration based on a calibration curve and their weight percentage from the CMC film. The assay was repeated 3 times.

In order to observe real time visualization of CMC hydrolysis, halo development was followed over time. Figure 3 shows the enzymatic hydrolysis of the film at different time points, between $5 \mathrm{~min}$ and $2 \mathrm{~h}$. A clear halo appeared in the film as early as $5 \mathrm{~min}$ after cellulase addition (Figure 3). While halo size mostly changed in the first hour and 
remained stable afterwards, we can see a gradual change in film color over time until a complete loss of orange color is achieved after $2 \mathrm{~h}$. This loss of color converts into a hole in the film with additional incubation time. This experiment was not designed for quantification since halo surface area can be correlated to enzyme concentration at the end of the reaction (as shown in Figure 2). The goal of this experiment was to show the feasibility of our system in real-time visualization of cellulase secretion for future studies, examining the cellulase secretion of live microorganisms. Detection of cellulase activity in other studies has been performed in various methods. Some of which occur in a liquid environment, and some on a plate surface. Either way, the detection for cellulase activity requires additional steps such as viscosity measurements ${ }^{46,47}$, detection of hydrolysis products ${ }^{41,43}$, adding dye to plates ${ }^{19,21,48}$ and others ${ }^{34,38,49}$. Incubation time for the hydrolysis reaction can vary between minutes and days, but the detection is not performed simultaneously with the reaction. This is due to the fact that the purpose of those studies was to find better, faster and more accurate methods to detect cellulase activity in microorganisms. Our goal, however, is to track this activity to better understand the effect of the surface on the microorgnisms activity. Hence, for this purpose a real-time visualization is critical.

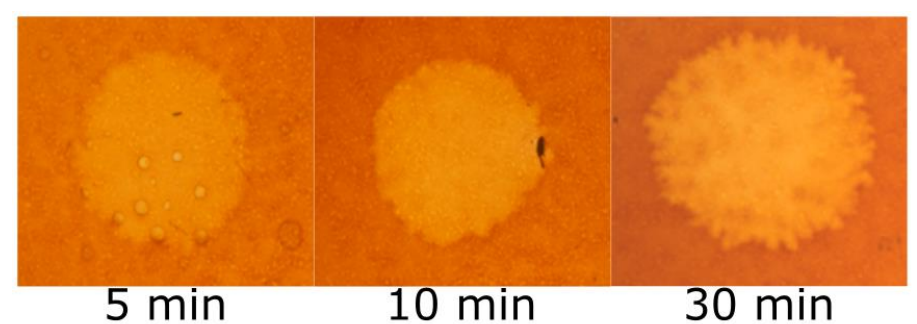

Figure 3: Effect of incubation time. six different dyed CMC films were subjected to 10 $\mu \mathrm{l}$ containing $10 \mu \mathrm{g}$ of cellulase. The films were incubated at $37^{\circ} \mathrm{C}$ for different time periods, between $5 \mathrm{~min}$ and $2 \mathrm{~h}$ (as indicated under the tiles), then washed and visualized. The halo

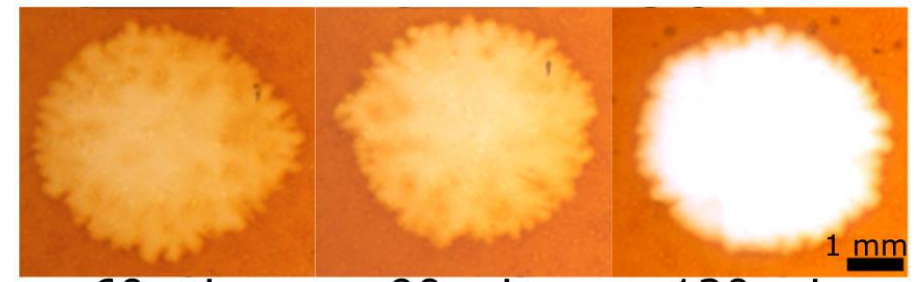
becomes bigger and brighter with time. Importantly, we can see halo within 5 min, validating this method as real-time visualization of cellulase activity.

\section{$60 \min \quad 90 \min \quad 120 \mathrm{~min}$}

To further characterize the system, we tested the reaction at different temperatures and $\mathrm{pH}$ values. Our initial studies were performed at $\mathrm{pH}=5$ and $37^{\circ} \mathrm{C}$, as these are the ideal parameters for the specific cellulase variety we used, according to manufacturer. Ideal $\mathrm{pH}$ and temperature conditions for the hydrolysis reaction highly depend on the source of cellulase. And indeed, many studies performed on different cellulase sources showed different ideal temperature and $\mathrm{pH}$ conditions $\mathrm{s}^{29,31,32,34}$. While mostly ideal $\mathrm{pH}$ conditions were around $\mathrm{pH}=5$, temperature conditions varied greatly between $30^{\circ} \mathrm{C}$ and $50^{\circ} \mathrm{C}$. It was important to us to show that our system can be sensitive enough to show hydrolysis even in less than ideal conditions. We varied the temperature by $10^{\circ} \mathrm{C}$ in each direction (Figure $4 \mathrm{~A}$ ). $27^{\circ} \mathrm{C}$ is an important temperature to examine since this is the ideal temperature for the model organism we aimed to test $(\mathrm{RKN})^{50}$. We found, as expected, that at this temperature the hydrolysis is less efficient. Nonetheless, halo is clearly visible and hence quantifiable although lowering the temperature may affect the sensitivity of the assay (Figure 4A). Since soil can reach very high temperatures during the summer, which can affect microorganism behavior ${ }^{51}$, we also tested hydrolysis visualization at $47^{\circ} \mathrm{C}$. This temperature was also less efficient than $37^{\circ} \mathrm{C}$ but to a lower extent than $27^{\circ} \mathrm{C}$ (Figure 4A). This demonstrates that the newly developed assay can be used in a wide range of temperatures according to the optimal environmental temperature of the microorganism tested. We next tested CMC hydrolysis at 
various $\mathrm{pH}$, ranging between 3 and 6 (Figure 4B). The reaction occurred at all $\mathrm{pH}$ values tested, though it was less efficient when deviating from the optimal $\mathrm{pH}$. Changing the conditions to more acidic conditions decreased the efficiency more than changing to more basic conditions (Figure 4B). Since most biological organisms flourish at a pH higher than 5, this means that the newly established method can be used to test cellulase activity in a wide range of microorganisms.

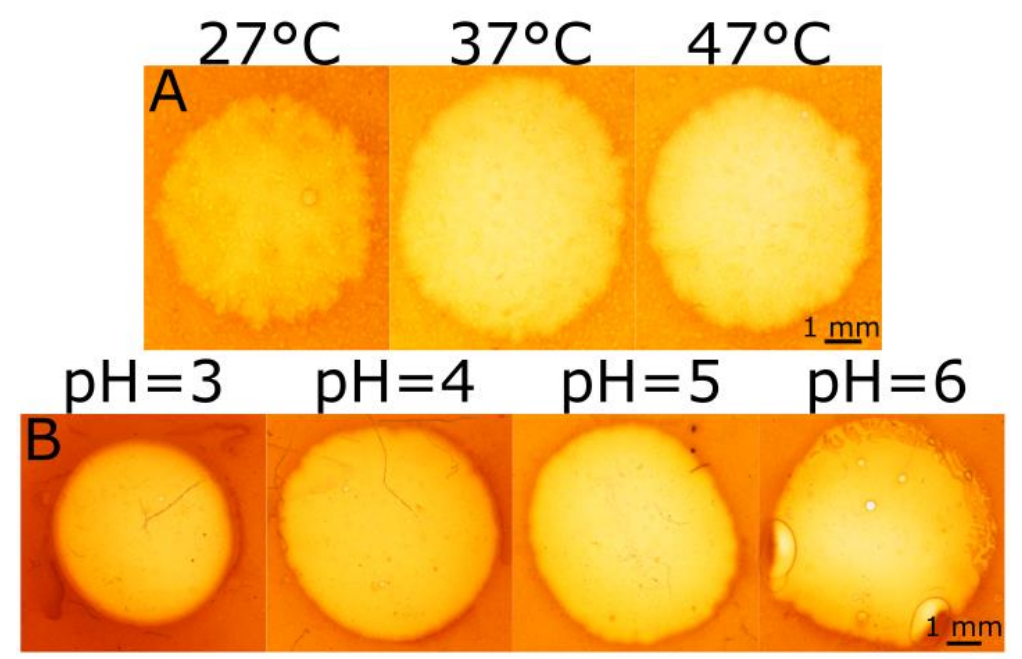

Figure 4: Effect of temperature and pH. A. Dyed CMC films were subjected to $10 \mu \mathrm{l}$ containing $10 \mu \mathrm{g}$ of cellulase and incubated for $2 \mathrm{~h}$ at 3 different temperatures $\left(27^{\circ} \mathrm{C}\right.$, $37^{\circ} \mathrm{C}$ and $\left.47^{\circ} \mathrm{C}\right)$. The films were then washed and visualized using a streomicroscope. The halo was biggest and brightest at $37^{\circ} \mathrm{C}$. B. The dyed CMC films were washed with acetate buffer at different $\mathrm{pH}$ values $(3,4,5$ and 6$)$ and then subjected to $10 \mu \mathrm{g}$ cellulase enzyme in $10 \mu \mathrm{l}$ of the same $\mathrm{pH}$ as the acetate buffer. The films were then incubated at $37^{\circ} \mathrm{C}$ for $2 \mathrm{~h}$ followed by washing and visualization.

To test our newly developed visualization technique in a physiologically relevant scenario, we chose to visualize interactions with Root Knot Nematode (RKN). RKN is a widespread root pathogen that penetrates the root by secreting Plant Cell Wall Degrading Enzymes (PCWDE) including cellulase ${ }^{52-54}$, causing substantial damage to crops around the world ${ }^{22,55-58}$. We applied $\mathrm{RKN}$ to the center of the dyed $\mathrm{CMC}$ film and incubated for $2 \mathrm{~h}$ at either $37^{\circ} \mathrm{C}$ (ideal temperature for the hydrolysis reaction) or $27^{\circ} \mathrm{C}$ (ideal temperature for $\mathrm{RKN}$ ). We found that the color change pattern differed from the one observed with application of pure enzyme. Unlike the pure enzyme, there was no single halo formed in the film, rather there were many small halos correlating to nematode location on the film (Figure 5A). This shows that diffusion of the reaction is well inhibited making the spatial sensitivity of the assay sufficient to detect a single nematode. Indeed, the number of halos correlates with the number of RKNs applied (Figure 5A). The halos at $27^{\circ} \mathrm{C}$ were smaller than the ones formed at $37^{\circ} \mathrm{C}$. We believe this is the result of lower efficiency of the hydrolysis reaction at $27^{\circ} \mathrm{C}$. It should be noted that $\mathrm{RKN}$ is an obligate parasite, meaning, it cannot survive for long time outside the plant ${ }^{59}$. Under ideal in-vitro conditions, kept at a low temperature, RKN will survive for a few days. Under our conditions, at a higher temperature and, more importantly, at relatively dry conditions, RKN cannot survive for more than a few hours. Hence, we did not expect high motility of RKN. However, we observed that RKN actively secrete cellulase for at least $2 \mathrm{~h}$. Since we saw that at a lower temperature the reaction is significantly less efficient, this could damage our resolution and ability to view the reaction at early stages and should be addressed later on, probably either by applying less than ideal conditions to the RKN, in which we already established their functionality, or by using higher resolution microscopy methods. During the development of this method, we only used stereomicroscope imaging, as we aimed at keeping the systems' simplicity. However, a higher resolution microscope will allow us to better view the reaction at lower efficiencies. 
To further explore cellulase secretion activity by microorganisms under natural-like conditions, specifically the influence of added natural additives, we added, as a biochemical factor, simulating root-secreted factors. We added root extract to the dyed CMC films and subjected it to nematodes in parallel to films with no root extract added to it (Figure 5B). Root extracts of target plants are known to influence RKN behavior and pathogenesis and are widely investigated $^{60-62}$. Additional work is being performed on natural additives as a means of RKN control ${ }^{63-65}$. In our system, the addition of root extract to the film resulted in a higher CMC hydrolysis, and visualized by a clear halo on the film, similar to the halo formed by using a purified enzyme. This contrast with RKN behavior in the absence of root extract where several small halos were formed in areas of cellulase secretion (Figure 5B). We assume that the halo was formed due to a high secretion of cellulase, resulting in the formation of a distinct, singular large halo. This can be evident by the uneven color of the halo, which is lighter where the nematodes - the sole source of cellulase in this assay, are located. Additionally, it is possible that the addition of root extract extended the viability of the nematodes due to more natural conditions. When subjecting the CMC film with root extract to pure enzyme, no difference in reaction, compared to film with no extract added, was observed (data not shown). This supports the claim that the difference observed in Figure 5B originated from the nematodes and not from a change in the film of hydrolysis reaction due to the addition of root extract. These results demonstrate our ability to visualize different degrees of cellulase activity by microorganisms, and to incorporate relevant natural additives into our system to better depict the specific contribution of different factors. Thus, importantly, our synthetic system is successful in testing the effect of different parameters on microorganism behavior. We have shown that natural additives can be incorporated into our system, and that those additives influence microorganismal behavior in the relevant context. Our next steps will include separation of root materials and controlled addition of isolated substances. We will also work on adding those substances with a spatial resolution to further link between topographical (physical) and chemical effects on microorganismal behavior on surfaces.

Figure 5: CMC Hydrolysis by Root knot nematodes. $\sim 80$ nematodes in $50 \mu \mathrm{l}$ were applied to the center of a dyed CMC film without (A) or with (B) root extract. A. The films were incubated for $2 \mathrm{~h}$ at either $27^{\circ} \mathrm{C}$ - the ideal temperature for RKN (left), or $37^{\circ} \mathrm{C}$ - the ideal temperature for the CMC hydrolysis reaction (right). The films were washed and visualized. In both temperatures hydrolysis could be visualized in the form of many spots of color change (marked with blue arrows). The spots on the film incubated at $37^{\circ} \mathrm{C}$ were larger and clearer due to the higher efficiency of the hydrolysis reaction in that temperature. An enlargement of one of the spots clearly shows the nematodes located in that spot. B. A comparison between the visualization of cellulase secretion by RKN on a film containing (right side, marked with + ) and not containing (left side, marked with -) root extract. The addition of root extract to the film resulted in a clear halo as opposed to the singular spots on the film not containing the root extract, probably due to increased cellulase secretion. The nematodes are marked with green arrows.

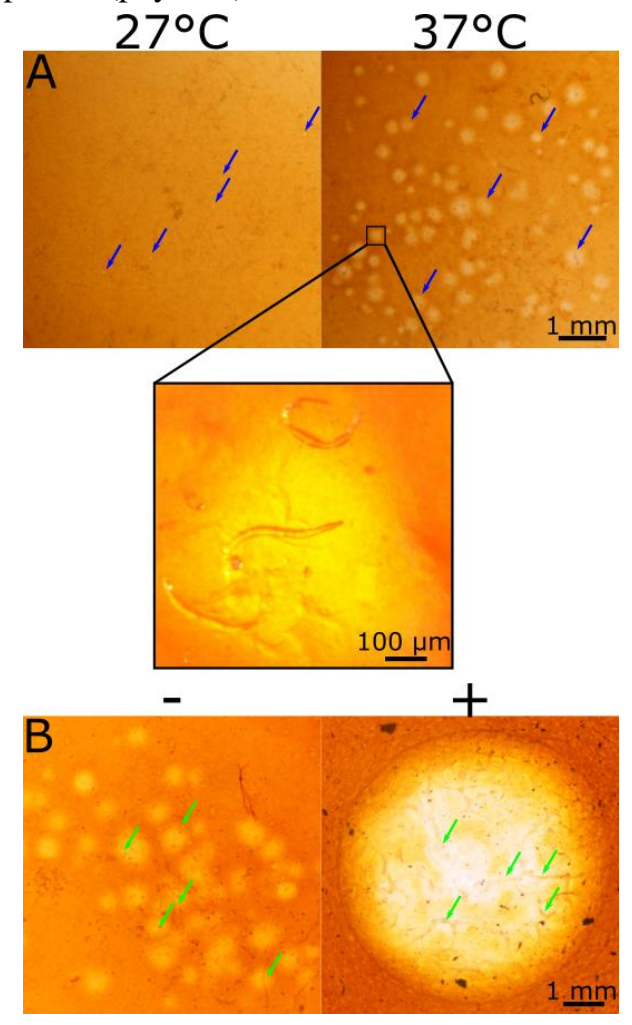


Different hydrolysis conditions can affect surface structure and so, we analyzed the surface of our films after they were subjected to enzymatic hydrolysis. We used SEM to view a non-hydrolyzed film and compared it to the surface of films subjected to $10 \mu \mathrm{g}$ of cellulase or RKN (Figure 6). The surface of unreacted film was completely smooth (Figure 6A). In contrast, both the film subjected to cellulase (Figure 6B) and the film subjected to RKN (Figure 6C and D) show rough areas. The pattern of the areas was different between the two treatments (compare Figure 6B to Figure $6 \mathrm{C}$ and D). In the RKN treatment, the rough areas probably represent nematode location and are similar in size to the ones we saw under the stereomicroscope (compare Figure5A to Figure 6C). The roughness formed by the cellulase enzyme, however, is more dispersed upon the surface (Figure 6B). SEM visualization of various CMC films was performed in the past, especially in the context of edible and anti-microbial film, which are incorporated with nano-particles or essential oils for that purpose ${ }^{66-69}$. Hence, SEM images of pure CMC films are scarce, yet the few found resemble the films we observe and slight changes can be attributed to the acridine orange added to our films.
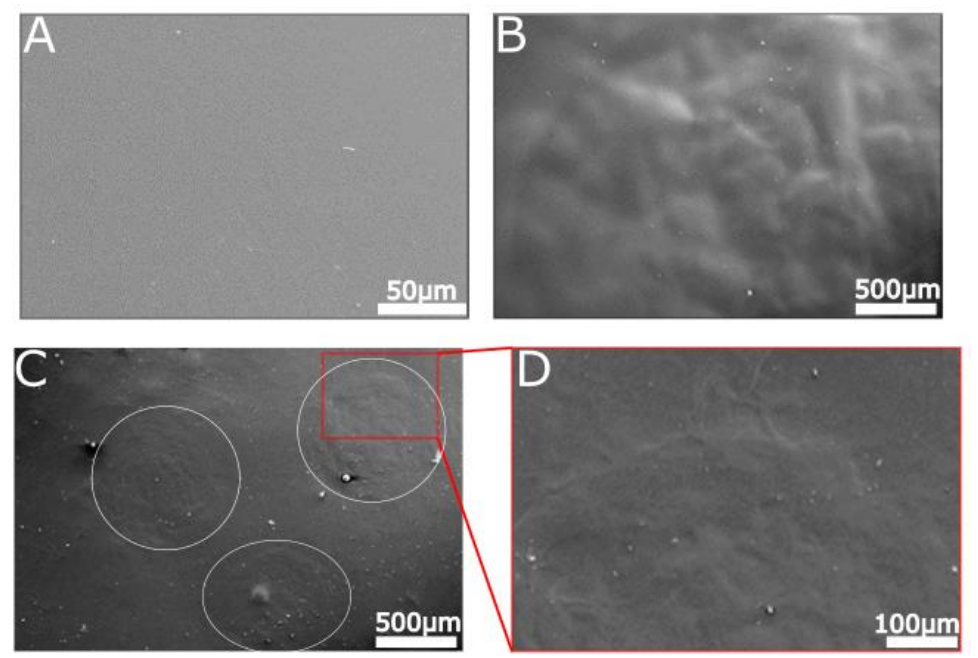

Figure 6: SEM analysis of unhydrolyzed and hydrolyzed CMC films. SEM micrographs of pure CMC film (A), CMC film subjected to $10 \mu \mathrm{g}$ of cellulase enzyme in volume of $10 \mu \mathrm{l}(\mathrm{B})$ and $\mathrm{CMC}$ film subjected to nematodes $(C$ and $D)$. While the pure CMC film presents a smooth surface, both films subjected to enzyme show a rough pattern. In the film subjected to nematodes, the nematodes location can be seen clearly (C, marked with white circles). All films were incubated at $37^{\circ} \mathrm{C}$ for $2 \mathrm{~h}$ with or without enzyme from any source and washed prior to coating for SEM visualization.

To quantify the qualitative phenomenon we observed with the SEM, we further studied the different surfaces using AFM analysis, which is ideal for quantitative measurement of surface roughness and nano-texture. We performed AFM on a non-hydrolyzed CMC film as well as films subjected to both $10 \mu \mathrm{g}$ of enzyme and RKN (Figure 7). Using AFM, we could see that the untreated CMC film had a regular pattern with small periodic holes about $10 \mathrm{~nm}$ in size (Figure 7A). AFM measurements on pure CMC films have been performed in the past especially in the context of nano particles incorporation ${ }^{70,71}$. However, it is important to mention that the roughness of the surface will highly depend on the particular setting, specifically the viscosity and modification ratio of CMC used as well as the percentage of CMC dissolved in the solvent. In conditions similar to the ones used here, the same periodic pattern was observed in pure $\mathrm{CMC}$ film ${ }^{70}$, though we could not find any data regarding films hydrolyzed by cellulase. On the contrary, the process of cellulose hydrolysis has been studied using $\mathrm{AFM}^{72,73}$, showing the directionality of hydrolysis in the contexts of cellulose fibers orientation. This type of hydrolysis is less relevant in our CMC films but is critical once we move to materials that resemble even more to the natural surface of roots. We calculated the roughness of the surface and found that the Root Mean Square (RMS) of the pure CMC film is $17.9 \mathrm{~nm}$ (Figure 7A). When the film was subjected to hydrolysis, from any of the two sources we used (enzyme or RKN), the roughness increased (Figure 7B and C). Films subjected to cellulase, showed a variety of hole sizes, with no specific pattern (Figure 7B, marked with green arrows). The holes in the film subjected to RKN were smaller than the ones in the film subjected to 
cellulase, but still larger than those in the untreated film (Figure 7C, marked with green arrows). Both films subjected to hydrolysis show a higher roughness than the untreated film. The RMS of the film subjected to nematodes was about twice the one of the untreated film (34.4nm, Figure 7C). The RMS of the film subjected to enzyme had an even higher RMS (40.6nm, Figure 7B). This may suggest that the hydrolysis by RKN is more spread out on the surface with a lower penetration into the film as compared to the pure enzyme hydrolysis.

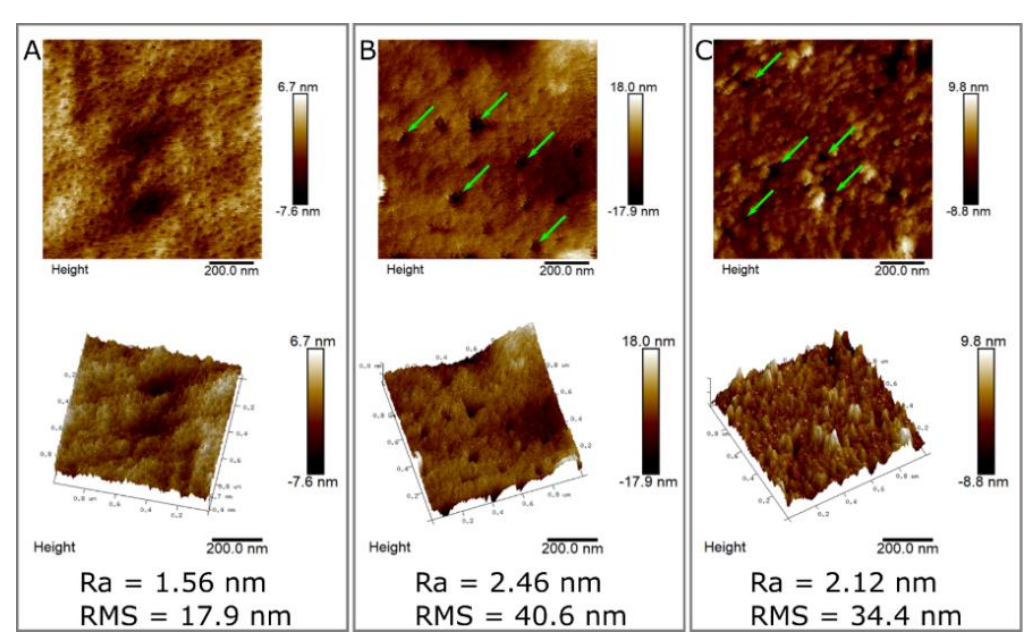

Figure 7: Surface topography measurement of unhydrolyzed and hydrolyzed CMC. 2D (upper panel) and 3D (lower panel) AFM images of pure CMC film (A), CMC film subjected to 10 $\mu \mathrm{g}$ of cellulase enzyme (B) and CMC film subjected to nematodes (C). Pure CMC film has small holes and low roughness. Both of the films subjected to enzyme show larger holes (marked with green arrows) and a higher roughness. In the film subjected to nematodes, the holes are smaller, and roughness is lower than the film subjected to cellulase. Roughness values are shown on the bottom. All films were incubated at $37^{\circ} \mathrm{C}$ for $2 \mathrm{~h}$ with or without enzyme or RKN and washed prior to AFM analysis.

In summary, we developed and analyzed a reliable and robust method for real-time visualization and semiquantification of cellulase activity. We used acridine orange with $\mathrm{CMC}$ to generate a film that changes color upon CMC hydrolysis. We characterized both the hydrolysis reaction and the surface of the films upon the reaction. We showed that it is possible to stray from ideal hydrolysis reaction conditions in both temperature and $\mathrm{pH}$. Additionally, we quantified the visualization of the hydrolysis as it correlates with enzyme concentration applied on the surface. We confirmed this by quantification of reduced sugars generated from this hydrolysis. We furthermore characterized the topography of the surface before and after hydrolysis both qualitatively and quantitatively. Lastly, we used RKN as a model microorganism and showed that they are active on the film and can hydrolyze it. We also showed that their activity is influenced by natural additives added to the film.

Our method allows for a simple and fast detection of cellulase activity on films. This method also does not require post hydrolysis dyeing as most other methods ${ }^{19-21,39}$ since the dye is already incorporated in the film. This is an improvement over previous methods, as we can therefore visualize CMC hydrolysis in real-time. This is important for our goal to develop this method to follow microorganism activity, i.e. cellulase secretion, as it occurs.

This work is a continuation of our previous work $^{27}$ where we built a synthetic replication of the root surface microstructure to better understand how microtopography influences microorganism location on the root surface. This system was built as a simplified model of a root-microorganism interaction, focusing on the structural/physical aspect of this interaction. A critical part of the root-microorganism interaction is the penetration of the microorganism into the root, which is often performed by secretion of cellulase and other enzymes ${ }^{54,74-76}$. A combination of the method developed here for a real-time visualization of cellulase secretion by microorganisms with the previous method we developed for root surface microstructure replication, will lead to a new avenue in the study of root-microorganism 
interactions. The combination of the two methods can enable real-time visualization of both microorganism location (through known tagging methods, if needed) and activity in the form of cellulase secretion, on the root surface topography. This elaborated synthetic system can help researchers separate different parameters of this interaction, starting from the structural parameter and combining it with different chemical parameters, to get a better insight into the complex interactions between root and microorganisms occurring on the surface of the root. Such research can assist in finding new routes for pathogen resistance in plants. Structural based resistant has not yet been studied and could lead to new avenues in the areas of pest control and biological pest control.

\section{Materials and Methods}

Preparation of acridine orange-CMC films: $20 \mathrm{mg}$ of acridine orange hemi (Zinc chloride) salt (A6014, Sigma Aldrich, St. Louis, MO, USA) dye was placed in $50 \mathrm{ml}$ distilled water and stirred for $60 \mathrm{~min}$. In parallel, 2 gr of Carboxymethyl cellulose (CMC) sodium salt, medium viscosity (C4888, Sigma Aldrich, St. Louis, MO, USA) powder was thoroughly dispersed in $50 \mathrm{ml}$ distilled water and stirred for $60 \mathrm{~min}$. After complete dispersion, the CMC solution was added to the dye solution. The whole mixture was stirred for $24 \mathrm{~h}$ at room temperature under dark conditions. 10 $\mathrm{ml}$ of the CMC sodium salt tagged with dye solution was spread onto a petri dish. The solution was dried under a hood overnight and a smooth film was obtained. All further investigations were performed on the films within the petri dishes.

Buffer and enzyme preparation: $0.1 \mathrm{M}$ of acetate buffer was prepared by fully dissolving 4 gr of sodium acetate anhydrous (GR, Sinopharm Chemical Reagent Co., Ltd., China) in $400 \mathrm{ml}$ of deionized water. $0.9 \mathrm{ml}$ of acetic acid (AR, Beijing Tongguang Fine Chemicals Co., Ltd., China) was added to the solution. The solution was then made up to a total of $500 \mathrm{ml}$ using deionized water. The $\mathrm{pH}$ of the resulting buffer solution was approximately 5 . Enzyme solution was prepared by dissolving the enzyme (Cellulase onozuka from T.reesei C8546-10KU, ATCC2692, 0.47 FPU/mg, Sigma- Aldrich) in the buffer solution to all desired concentrations used in the experiments.

CMC film hydrolysis: $20 \mathrm{ml}$ acetate buffer (0.1M) was poured on two films. After $1 \mathrm{~min}$, the films gained a jell-like texture, and the buffer solution was removed and replaced by $10 \mu \mathrm{l}$ of either buffer solution or enzyme solution $(1 \mu \mathrm{g} / 1 \mu \mathrm{l})$ which were added on to the center of the film. Both films were incubated at $37^{\circ} \mathrm{C}$ for $2 \mathrm{~h}$. After $2 \mathrm{~h}$ the films were washed with 5 or $20 \mathrm{ml}$ water each and dried under the hood for $2 \mathrm{~h}$. The washing solutions were kept in a vial for further analysis. The films were then visualized using a Nikon smz 25 stereomicroscope equipped with NISelements software and an image was captured using Nikon DS-Ri2 camera.

The same method was used to assess the effect of different parameters on the film hydrolysis:

1. Time: Six CMC films were incubated at $37^{\circ} \mathrm{C}$ and removed at different time points - after $5 \mathrm{~min}, 15 \mathrm{~min}, 30$ $\min , 60 \mathrm{~min}, 90 \mathrm{~min}$ and $120 \mathrm{~min}$.

2. Enzyme concentration: Seven different concentrations of cellulase enzyme were prepared in acetate buffer $(1,2,5,10,15,20$ and $30 \mu \mathrm{g}$ in $10 \mu \mathrm{l})$. Solutions with different enzyme concentrations were added to four different locations on the same film. The film was incubated at $37^{\circ} \mathrm{C}$ for $2 \mathrm{~h}$. 
3. Temperature: Three CMC films were used for temperature dependence experiment. The experiment was performed with $10 \mu \mathrm{g}$ of enzyme and an incubation time of $2 \mathrm{~h}$. The films were incubated at 3 different temperatures: $27^{\circ} \mathrm{C}, 37^{\circ} \mathrm{C}$ and $47^{\circ} \mathrm{C}$.

4. pH: Four acetate buffer solutions at different $\mathrm{pH}$ values $(3,4,5,6)$ were prepared by titration with $\mathrm{HCl}$ or $\mathrm{KOH}$. Four separate dyed CMC films were taken and each one was washed with one of the buffers for 1 min. The experiment was performed with $10 \mu \mathrm{g}$ of enzyme and incubation for $2 \mathrm{~h}$ at $37^{\circ} \mathrm{C}$.

All experiments were run in triplicates.

Benedict's test: Reaction products in film wash $(20 \mathrm{ml})$ of either buffer or enzyme were concentrated to $2 \mathrm{ml}$ by evaporation at $60^{\circ} \mathrm{C}$. The solution was then cooled down to room temperature. $0.2 \mathrm{ml}$ of Benedict's reagent (Sigma Aldrich, Dorset, England) was added to the vial. The vial was then boiled for 3-4 minutes. Color change was then qualitatively examined.

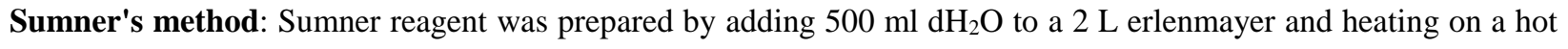
plate at a low temperature. Then $300 \mathrm{~g}$ Potassium sodium tartarate (S-2377 Sigma Aldrich, St. Louis, MO, USA) was added and mixed. $200 \mathrm{ml} \mathrm{NaOH} 2 \mathrm{~N}$ (MERCK 6498) was then added. Next, 10g 3,5 Dinitrosalicilic acid (D-0550 Sigma Aldrich, St. Louis, MO, USA) was added and dissolve completely. The solution was cooled and completed to $1 \mathrm{~L}$ with $\mathrm{dH}_{2} \mathrm{O}$. The solution was then kept in a dark bottle at room temperature for later use. To quantitatively test the reducing sugars in the wash solution, $0.5 \mathrm{ml}$ of reaction products in film wash $(5 \mathrm{ml})$ of different enzyme concentrations were added to $0.5 \mathrm{ml}$ of Sumner reagent. The mixture was incubated in a boiling water bath for $5 \mathrm{~min}$. Color change was then examined using UV-vis absorbance at $510 \mathrm{~nm}$. Absorption studies were carried out at room temperature on a UV-vis spectrophotometer (Hewlett- Packard, model 8453) from 200 to $600 \mathrm{~nm}$ using a quartz cell (10 mm path length). For calibration, known amounts of glucose were subjected to the same process. The amount of glucose in the wash solution was then calculated and given as the percentage of the original CMC weight added to the film.

Acridine orange measurements: Known amounts of acridine orange were dissolved in $2 \mathrm{ml}$ of deionized water. Quantification was performed at $480 \mathrm{~nm}$, the $\lambda$ max of acridine orange. The measured absorbance was used to generate a calibration curve, based on Beer's law. To measure the amount of acridine orange released during film hydrolysis, CMC films were washed with $5 \mathrm{ml}$ of water which were stored at RT for later use. The film wash of different concentrations were analyzed by absorbance measurement using UV-vis spectroscopy. Background UV-vis spectra of the water used for initial film wash were subtracted from the spectra of the cellulose hydrolysate solution. Dye concentration in each solution was calculated based on the calibration curve and given as percentage of dye added to the film.

Root knot nematode (RKN; Meloidogyne javanica) preparation: RKN were propagated on greenhouse-grown tomato 'Avigail' (870) plants. Nematode egg masses were extracted from roots with $0.05 \%(\mathrm{v} / \mathrm{v})$ sodium hypochlorite followed by sucrose flotation. For sterilization, eggs were placed on a cellulose-acetate filter membrane (Sartorius Stedim Biotech $\mathrm{GmbH}$, Goettingen, Germany, pore size $5 \mu \mathrm{m}$ ) in a sterile Whatman ${ }^{\circledR}$ filter holder (Whatman International Ltd., Dassel, Germany). Eggs on the filter were exposed for $10 \mathrm{~min}$ to $0.01 \%$ (w/v) mercuric chloride (Sigma-Aldrich, St Louis, MO, USA), followed by $0.7 \%$ (v/v) streptomycin solution (Sigma-Aldrich), and three 
washing steps with $50 \mathrm{ml}$ sterilized distilled water. The sterilized eggs were collected from the membrane and placed on 25- $\mu \mathrm{m}$-pore sieves in 0.01M 2-morpholinoethanesulfonic acid buffer (Sigma-Aldrich) under aseptic dark conditions for 3 days, allowing $\mathrm{J} 2$ s to hatch. For the RKN J2 is the infective stage which penetrates the root elongation zone toward the vascular cylinder to initiate infection. Freshly hatched preparasitic J2s were collected in a $50 \mathrm{ml}$ falcon tube. For visualization of RKN cellulase secretion test, $50 \mu \mathrm{l}$ containing $\sim 80$ nematodes were added to the center of dyed CMC films pre-treated by acetate buffer as described above. Films were incubated at either $27^{\circ} \mathrm{C}$ or $37^{\circ} \mathrm{C}$ for $2 \mathrm{~h}$ and then thoroughly washed with water 2-3 times. The films were then used for visualization by stereomicroscope, Scanning electron microscopy (SEM) and Atomic force microscopy (AFM).

Root extract addition to CMC film: Tomato cultivar M82 roots were physically crushed using mortar and pestle. The resulting solution was filtered using gauze. The filtered liquid was used instead of water in the dissolution process of CMC during the preparation of the dyed CMC film. The film was then prepared and exposed to RKN as described above.

Scanning Electron Microscopy (SEM) visualization: Scanning was performed by S-3400N, Hitachi, Japan at an accelerating voltage of $20 \mathrm{kV}$. The surface was coated by gold using a sputter coater (E-1010, Hitachi, Japan) before visualization.

Atomic Force Microscopy (AFM) visualization: AFM topographic imaging was performed using an Innova Atomic Force Microscope with a NanoDrive Controller (Bruker, California). Small pieces of film were glued onto metal disks and attached to a magnetic sample holder located on the top of the scanner tube. Phase images were recorded under ambient air conditions. AFM images were taken with a scan rate of $1.00 \mathrm{~Hz}$ using tapping mode. Scan sizes were 1$10 \mu \mathrm{m}$ with 256 scans on each scanning line.

\section{Acknowledgments:}

We would like to thank Dr. Einat Zelinger and the Center for Scientific Imaging (CSI) at the Faculty of Agriculture, Hebrew University, Rehovot for their assistance with SEM imaging. We would like to thank Hanita Zemach from the

Histology unit at Volcani Center for her help with stereomicroscope visualization. Research was supported by seed funds from The Agricultural Research Organization to MK.

\section{References}

1. Genet, M. et al. The influence of cellulose content on tensile strength in tree roots. Plant Soil 278, 1-9 (2005).

2. Akkerman, M. et al. Texture of cellulose microfibrils of root hair cell walls of Arabidopsis thaliana, Medicago truncatula, and Vicia sativa. J. Microsc. 247, 60-67 (2012).

3. Barthlott, W., Mail, M., Bhushan, B. \& Koch, K. Plant Surfaces: Structures and Functions for Biomimetic Innovations. Nano-Micro Lett. 9, 23 (2017).

4. Sundarraj, A. A. \& Ranganathan, T. V. A review on cellulose and its utilization from agro-industrial waste. Drug Invent. Today 10, 89-94 (2018).

5. Deng, J., Xiong, T., Wang, H., Zheng, A. \& Wang, Y. Effects of cellulose, hemicellulose, and lignin on the 
structure and morphology of porous carbons. ACS Sustain. Chem. Eng. 4, 3750-3756 (2016).

6. Zhang, J. et al. Cellulose-hemicellulose and cellulose-lignin interactions during fast pyrolysis. ACS Sustain. Chem. Eng. 3, 293-301 (2015).

7. Credou, J. \& Berthelot, T. Cellulose: From biocompatible to bioactive material. J. Mater. Chem. B 2, 47674788 (2014).

8. Altaner, C. M., Thomas, L. H., Fernandes, A. N. \& Jarvis, M. C. How cellulose stretches: Synergism between covalent and hydrogen bonding. Biomacromolecules 15, 791-798 (2014).

9. Payne, C. M. et al. Fungal cellulases. Chem. Rev. 115, 1308-1448 (2015).

10. Singh, A. \& Singh, I. K. molecular aspects of plant-pathogen interaction. (2018).

11. Adewuyi, Y. G. \& Deshmane, V. G. Intensification of Enzymatic Hydrolysis of Cellulose Using HighFrequency Ultrasound: An Investigation of the Effects of Process Parameters on Glucose Yield. Energy and Fuels 29, 4998-5006 (2015).

12. Satari, B., Karimi, K. \& Kumar, R. Cellulose solvent-based pretreatment for enhanced second-generation biofuel production: A review. Sustainable Energy and Fuels vol. 3 (2019).

13. Lynd, L. R., Weimer, P. J., Zyl, W. H. Van \& Isak, S. Microbial Cellulose Utilization : Fundamentals and Biotechnology Microbial Cellulose Utilization : Fundamentals and Biotechnology Downloaded from http://mmbr.asm.org/ on February 6, 2013 by INDIAN INSTITUTE OF TECHNOLOGY MADRAS. Microbiol. Mol. Biol. Rev. 66, 506-577 (2002).

14. Dashtban, M., Maki, M., Leung, K. T., Mao, C. \& Qin, W. Cellulase activities in biomass conversion: Measurement methods and comparison. Crit. Rev. Biotechnol. 30, 302-309 (2010).

15. Dashtban, M., Schraft, H. \& Qin, W. Fungal bioconversion of lignocellulosic residues; Opportunities \& perspectives. Int. J. Biol. Sci. 5, 578-595 (2009).

16. Hankin, L. \& Anagnostakis, S. L. Solid media containing carboxymethylcellulose to detect Cx cellulase activity of micro organisms. J. Gen. Microbiol. 98, 109-115 (1977).

17. Zhang, Y. H. P., Hong, J. \& Ye, X. Cellulase Assays. In: Mielenz J. (eds) Biofuels. Methods Mol. Biol. 581, (2009).

18. Yeoh, H. H., Khew, E. \& Lim, G. A Simple Method for Screening Cellulolytic Fungi. Micologia 77, 161$162(1985)$.

19. Kasana, R. C., Salwan, R., Dhar, H., Dutt, S. \& Gulati, A. A rapid and easy method for the detection of microbial cellulases on agar plates using Gram's iodine. Curr. Microbiol. 57, 503-507 (2008).

20. Johnsen, H. R. \& Krause, K. Cellulase activity screening using pure carboxymethylcellulose: Application to soluble cellulolytic samples and to plant tissue prints. Int. J. Mol. Sci. 15, 830-838 (2014).

21. Meddeb-Mouelhi, F., Moisan, J. K. \& Beauregard, M. A comparison of plate assay methods for detecting extracellular cellulase and xylanase activity. Enzyme and Microbial Technology vol. 66 16-19 (2014).

22. Iberkleid, I., Sela, N. \& Brown Miyara, S. Meloidogyne javanica fatty acid- and retinol-binding protein (MjFAR-1) regulates expression of lipid-, cell wall-, stress- and phenylpropanoid-related genes during nematode infection of tomato. BMC Genomics 16, 272 (2015). 
23. Yang, M. et al. Plant-plant-microbe mechanisms involved in soil-borne disease suppression on a maize and pepper intercropping system. PLoS One 9, 1-22 (2014).

24. Cannesan, M. A. et al. Association between border cell responses and localized root infection by pathogenic Aphanomyces euteiches. Ann. Bot. 108, 459-469 (2011).

25. Doan, H. K. \& Leveau, J. H. J. Artificial Surfaces in Phyllosphere Microbiology. Phytopathology 105, 1036-1042 (2015).

26. Zhang, B. et al. Fabrication of biomimetically patterned surfaces and their application to probing plantbacteria interactions. ACS Appl. Mater. Interfaces 6, 12467-12478 (2014).

27. Kumari, P. et al. A biomimetic platform for studying root-environment interaction. Plant Soil 447, 157-168 (2020).

28. Mutalik, V. et al. Aqueous-Solution and Solid-Film Properties of Poly(vinyl alcohol), Poly(vinyl pyrrolidone), Gelatin, Starch, and Carboxymethylcellulose Polymers. J. Appl. Polym. Sci. 106, 765-774 (2007).

29. Islam, F. \& Roy, N. Screening, purification and characterization of cellulase from cellulase producing bacteria in molasses. BMC Res. Notes 11, 1-6 (2018).

30. Kumar, B. et al. Production, purification and characterization of an acid/alkali and thermo tolerant cellulase from Schizophyllum commune NAIMCC-F-03379 and its application in hydrolysis of lignocellulosic wastes. AMB Express 8, 173-188 (2018).

31. He, D., Bao, L., Long, Y., Wei, W. \& Yao, S. A new study of the enzymatic hydrolysis of carboxymethyl cellulose with a bulk acoustic wave sensor. Talanta 50, 1267-1273 (2000).

32. Liang, Y. L., Zhang, Z., Wu, M., Wu, Y. \& Feng, J. X. Isolation, screening, and identification of cellulolytic bacteria from natural reserves in the subtropical region of China and optimization of cellulase production by Paenibacillus terrae ME27-1. Biomed Res. Int. 2014, (2014).

33. Gupta, P., Samant, K. \& Sahu, A. Isolation of cellulose-degrading bacteria and determination of their cellulolytic potential. Int. J. Microbiol. 2012, (2012).

34. Paljevac, M., Primožič, M., Habulin, M., Novak, Z. \& Knez, Ž. Hydrolysis of carboxymethyl cellulose catalyzed by cellulase immobilized on silica gels at low and high pressures. J. Supercrit. Fluids 43, 74-80 (2007).

35. Zhou, Y. et al. Adsorption of cationic dyes on a cellulose-based multicarboxyl adsorbent. J. Chem. Eng. Data 58, 413-421 (2013).

36. Byvaltsev, V. A. et al. Acridine orange: A review of novel applications for surgical cancer imaging and therapy. Front. Oncol. 9, 1-8 (2019).

37. Lauretti, F. et al. Use of acridine orange staining for the detection of rotavirus RNA in polyacrylamide gels. Journal of Virological Methods vol. 114 29-35 (2003).

38. Sreenath, H. K. Hydrolysis of carboxymethyl cellulose by cellulase. LWT-Food Sci. Technol. 26, 224-228 (1993).

39. Teather, R. M. \& Wood, P. J. Use of Congo red-polysaccharide interactions in enumeration and 
characterization of cellulolytic bacteria from the bovine rumen. Appl. Environ. Microbiol. 43, 777-780 (1982).

40. Benedict, S. R. A reagent for the. J. Biol. Chem. 5, 485-487 (1908).

41. Ghose T. K. Measurment of cellulase activities. Pure Appl. Chem. 59, 257-268 (1987).

42. Wood, T. M. \& Bhat, K. M. Methods for measuring cellulase activities. Methods Enzymol. 160, 87-112 (1988).

43. Shuangqi, T., Zhenyu, W., Ziluan, F., Lili, Z. \& Jichang, W. Determination methods of cellulase activity. African J. Biotechnol. 10, 7122-7125 (2011).

44. Florencio, C., Couri, S. \& Farinas, C. S. Correlation between agar plate screening and solid-state fermentation for the prediction of cellulase production by trichoderma strains. Enzyme Res. 2012, 793708 (2012).

45. Carder, J. H. Detection and quantitation of cellulase by Congo red staining of substrates in a cup-plate diffusion assay. Analytical Biochemistry vol. 153 75-79 (1986).

46. Biology, P. \& February, R. Viscosimetric determination of cellulase activity: critical analyses. Plant Cell Physiol. 908, 899-908 (1976).

47. LEVINSON, H. S. \& REESE, E. T. Enzymatic hydrolysis of soluble cellulose derivatives as measured by changes in viscosity. J. Gen. Physiol. 33, 601-628 (1950).

48. Gohel, H. R., Contractor, C. N., Ghosh, S. K. \& Braganza, V. J. A comparative study of various staining techniques for determination of extra cellular cellulase activity on Carboxy Methyl Cellulose (CMC) agar plates. Int. J. Curr. Microbiol. Appl. Sci. 3, 261-266 (2014).

49. Nguyen, L. T., Neo, K. R. S. \& Yang, K. L. Continuous hydrolysis of carboxymethyl cellulose with cellulase aggregates trapped inside membranes. Enzyme Microb. Technol. 78, 34-39 (2015).

50. Diez, J. A. \& Dusenbery, D. B. Preferred Temperature of Meloidogyne incognita. J. Nematol. 21, 99-104 (1989).

51. Wang, K. H. \& McSorley, R. Exposure time to lethal temperatures for Meloidogyne incognita suppression and its implication for soil solarization. J. Nematol. 40, 7-12 (2008).

52. Smant, G. et al. Endogenous cellulases in animals: isolation of beta-1, 4-endoglucanase genes from two species of plant-parasitic cyst nematodes. Proc Natl Acad Sci U S A 95, 4906-4911 (1998).

53. Mitreva-dautova, M. et al. A Symbiont-Independent Endo-1,4- $\beta$-Xylanasefrom the Plant-Parasitic Nematode Meloidogyne incognita. Mol. plant-microbe Interact. 19, 521-529 (2006).

54. Mitsumasu, K., Seto, Y. \& Yoshida, S. Apoplastic interactions between plants and plant root intruders. Front. Plant Sci. 6, 1-17 (2015).

55. Danchin, E. G. J. et al. Multiple lateral gene transfers and duplications have promoted plant parasitism ability in nematodes. Proc. Natl. Acad. Sci. 107, 17651-17656 (2010).

56. Perry, R. N. \& Moens, M. Introduction to Plant-Parasitic Nematodes; Modes of Parasitism. (2011).

57. Adegbite, A. A. \& Adesiyan, S. O. Root Extracts of Plants to Control Root-Knot Nematode on Edible Soybean. J. Veg. Sci. 12, 5-12 (2006). 
58. Iberkleid, I. et al. Fatty Acid-and Retinol-Binding Protein, Mj-FAR-1 Induces Tomato Host Susceptibility to Root-Knot Nematodes. PLoS One 8, (2013).

59. Kennedy, M. W. \& Harnett, W. Parasitic nematodes: molecular biology, biochemistry and immunology. (2013).

60. Stetina, S. R., McGawley, E. C. \& Russin, J. S. Extraction of Root-associated Meloidogyne incognita and Rotylenchulus reniformis. J. Nematol. 29, 209-215 (1997).

61. Oota, M. et al. Identification of Naturally Occurring Polyamines as Root-Knot Nematode Attractants. Molecular Plant vol. 13 658-665 (2020).

62. Čepulyte, R., Danquah, W. B., Bruening, G. \& Williamson, V. M. Potent Attractant for Root-Knot Nematodes in Exudates from Seedling Root Tips of Two Host Species. Sci. Rep. 8, 1-10 (2018).

63. Kepenekçi, I., Erdoğuş, D. \& Erdoğan, P. Effects of some plant extracts on root-knot nematodes in vitro and in vivo conditions. Turkiye Entomoloji Derg. 40, 3-14 (2016).

64. Adegbite, A. A. \& Adesiyan, S. O. Root extracts of plants to control root-knot nematode on edible soybean. J. Veg. Sci. 12, 5-12 (2006).

65. Rady, M. M. The efficiency of some natural alternatives in root-knot nematode control. Adv. Plants Agric. Res. 8, 355-362 (2018).

66. Zhong, T., Oporto, G. S., Jaczynski, J., Tesfai, A. T. \& Armstrong, J. Antimicrobial properties of the hybrid copper nanoparticles-carboxymethyl cellulose. Wood Fiber Sci. 45, 215-222 (2013).

67. Martelli, S. M. et al. Edible carboxymethyl cellulose films containing natural antioxidant and surfactants: \&alpha-tocopherol stability, in vitro release and film properties. LWT-Food Sci. Technol. 77, 21-29 (2017).

68. Fattahi, R., Ghanbarzadeh, B. \& Bahrami, A. Effect of Emulsion Condition of Oil Phase on Microstructure and Anti-Fungal Properties of Emulsified Films Based on Carboxymethyl Cellulose. Int. J. Nutr. Sci. 3, 4449 (2018).

69. Biswas, A. et al. Preparation and Characterization of Carboxymethyl Cellulose Films with Embedded Essential Oils. J. Mater. Sci. Res. 7, 16 (2018).

70. Saladino, M. L. et al. Graphene Oxide Carboxymethylcellulose Nanocomposite for Dressing Materials. Materials (Basel). 13, (2020).

71. Nemazifard, M., Kavoosi, G., Marzban, Z. \& Ezedi, N. Physical, mechanical, water binding, and antioxidant properties of cellulose dispersions and cellulose film incorporated with pomegranate seed extract. Int. J.

Food Prop. 20, 1501-1514 (2017).

72. Quirk, A. et al. Direct visualization of the enzymatic digestion of a single fiber of native cellulose in an aqueous environment by atomic force microscopy. Langmuir 26, 5007-5013 (2010).

73. Liu, H., Fu, S., Zhu, J. Y., Li, H. \& Zhan, H. Visualization of enzymatic hydrolysis of cellulose using AFM phase imaging. Enzyme and Microbial Technology vol. 45 274-281 (2009).

74. Martin, F., Kohler, A., Murat, C., Veneault-Fourrey, C. \& Hibbett, D. S. Unearthing the roots of ectomycorrhizal symbioses. Nat. Rev. Microbiol. 14, 760-773 (2016).

75. Roy, A., Jayaprakash, A., Rajeswary T, R., Annamalai, A. \& Lakshmi, P. T. V. Genome-wide annotation, 
comparison and functional genomics of carbohydrate-active enzymes in legumes infecting Fusarium oxysporum formae speciales. Mycology 11, 56-70 (2020).

76. van der Does, H. C. \& Rep, M. Adaptation to the Host Environment by Plant-Pathogenic Fungi. Annu. Rev. Phytopathol. 55, 427-450 (2017). 